\title{
Proton magnetic resonance spectroscopy in frontotemporal lobar degeneration-related syndromes
}

Alexander G Murley $\mathrm{PhD}^{1,2}$, Kamen A Tsvetanov $\mathrm{PhD}^{1}$, Matthew A Rouse $\mathrm{MSc}^{1,3}$, P Simon Jones $\mathrm{MSc}^{1}$, Katrine Sværke MSc ${ }^{1}$, Win Li BSc ${ }^{2}$, T Adrian Carpenter $\mathrm{PhD}^{1}$, James B Rowe $\mathrm{PhD}^{1,2,3}$

Affiliations: 1. Department of Clinical Neurosciences, University of Cambridge, UK, 2. Cambridge University Hospitals NHS Foundation Trust, UK, 3. MRC Cognition and Brain Sciences Unit, University of Cambridge, UK.

Running header: MRS in FTLD-related syndromes

Contact information:

Alexander Murley Herchel Smith Building

Forvie Site

Cambridge

CB2 0SZ

am2505@medschl.cam.ac.uk

Search terms: Frontotemporal dementia, corticobasal degeneration, progressive supranuclear palsy, MRS, behavior.

Funding: This work was funded by the Holt Fellowship (RG86564), the Guarantors of Brain (G101149), the Wellcome Trust (103838), the PSP Association, the Medical Research Council (SUAG/051 G101400), the National Institute for Health Research (NIHR) Biomedical Research Centre and Biomedical Research Unit in Dementia based at Cambridge University Hospitals NHS Foundation Trust and the University of Cambridge (146281) and the Cambridge Centre for Parkinson Plus.

Acknowledgements: We thank the study participants and their families and carers, the radiographers at the Wolfson Brain Imaging Centre, University of Cambridge and Dr Dinesh Deelchand, University of Minnesota, for his MRSpa software (https://www.cmrr.umn.edu/downloads/mrspa/) and MRS basis set.

Disclosures: J.B.R. serves as an associate editor to Brain and is a non- remunerated trustee of the Guarantors of Brain, Darwin College Cambridge, and the PSP Association (UK). He has provided consultancy to Asceneuron, Biogen, UCB and has research grants from AZ-Medimmune, Janssen, Lilly and WAVE as industry partners in the Dementias Platform UK. The other authors have no disclosures. 
Murley et al. Page 2

\section{Abstract}

\section{Objective}

To measure cortical metabolite deficits in vivo in syndromes associated with frontotemporal lobar degeneration, in relation to cognitive and behavioral change.

\section{Methods}

Sixty patients were recruited with a clinical syndrome associated with frontotemporal lobar degeneration (behavioral variant frontotemporal dementia $\mathrm{n}=11$, progressive supranuclear palsy $\mathrm{n}=26$, corticobasal syndrome $\mathrm{n}=11$, primary progressive aphasias $\mathrm{n}=12$ ), and 38 age- and sexmatched healthy controls. We measured nine metabolites in the right inferior frontal gyrus, superior temporal gyrus and right primary visual cortex using 3T semi-laser magnetic resonance spectroscopy. Metabolite concentrations were corrected for age, sex, and partial volume. We related corrected metabolite concentrations to cognitive and behavioral measures using canonical correlation analysis.

\section{Results}

Metabolite concentrations varied significantly by brain region and diagnosis (region $\mathrm{x}$ metabolite $\mathrm{x}$ diagnosis interaction $\mathrm{F}_{(64)}=1.73$, $\mathrm{p}<0.001$, corrected for age, sex, and atrophy within the voxel). Nacetyl aspartate and glutamate concentrations were reduced in the right prefrontal cortex in behavioral variant frontotemporal dementia and progressive supranuclear palsy, even after partial volume correction. The reduction of these metabolites was associated with executive dysfunction and behavioral impairment (canonical correlation analysis $\mathrm{R}=0.95, \mathrm{p}<0.001$ ).

\section{Conclusion}

Magnetic resonance spectroscopy confirms behaviourally relevant metabolite deficits including glutamate, in syndromes associated with frontotemporal lobar degeneration. Magnetic resonance spectroscopy may be a useful index of neurodegeneration, and highlight candidates for pharmacological treatment. 


\section{Introduction}

Frontotemporal lobar degeneration (FTLD) is a heterogeneous group of diseases characterised by focal neurodegeneration of frontal, temporal and subcortical regions including the basal ganglia and midbrain. ${ }^{1}$ These progressive, incurable diseases cause a spectrum of clinical syndromes; behavioral variant frontotemporal dementia (bvFTD), primary progressive aphasias (PPA), progressive supranuclear palsy (PSP) and corticobasal syndrome (CBS). ${ }^{2-5}$ However the clinical phenotypes associated with FTLD are heterogeneous and overlapping in their features ${ }^{6}$, and include higher cognitive changes which cause a high burden on the patient and their families and carers. ${ }^{7,8}$. There is a pressing need for a better mechanistic understanding of their pathophysiology, in support of new treatment strategies.

Here, using magnetic resonance spectroscopy (MRS) we quantify in vivo the biochemical consequences of FTLD. Our aim was to compare metabolite profiles in the frontal and temporal lobes, the cortical regions most typically affected in FTLD, with the occipital lobe that is relatively spared by the diseases. We predefined the right inferior frontal and superior temporal gyri as regions of interest. These regions are affected by multiple FTLD syndromes ${ }^{1,9}$ and form part of a network regulating behavior. ${ }^{10,11}$ We tested the hypothesis that metabolites associated with neuronal structure and function would be reduced in the frontal and temporal lobes in disorders associated with FTLD, and that this metabolite deficit would correlate with the severity of cognitive and behavioral impairment.

\section{Methods}

\section{Participant recruitment and testing}

Participants were recruited as part of the PIPPIN ("Pick's disease and Progressive supranuclear palsy prevalence and incidence") study, an epidemiological cohort study of FTLD-related syndromes in the East of England. Details of the study have been reported elsewhere ${ }^{6,12,13}$. In brief, PIPPIN aimed to recruit all patients living with a FTLD syndrome in the UK counties of Cambridgeshire and Norfolk. All patients met the clinical diagnostic criteria for a principal FTLD syndrome ${ }^{2-5}$. We grouped all PSP phenotypes into the PSP group, and all progressive aphasia subtypes in to the PPA group, in view of the group size. Control participants with no neurological or psychiatric disease were recruited from the NIHR Join Dementia Research register. Participants were invited for clinical examination, cognitive testing, and MRI. Here, we report the subset of patients $(n=60)$ and age and sex matched healthy controls $(n=38)$ who completed magnetic resonance spectroscopy. All participants provided written informed consent or, if they lacked capacity to consent, their next of kin were consulted using the 'personal consultee' process established in UK law. The study had ethical approval from the Cambridge Central Research Ethics Committee (REC 12/EE/0475).

Each participant had a structured clinical examination which recorded the presence or absence of clinical features in the current consensus diagnostic criteria ${ }^{2-5}$. We grouped these features into behavior, language and sensorimotor "scores" based on the sum of features in each group. The behavior score comprised impulsivity, apathy, loss of empathy, stereotyped and/or compulsive 
behaviors, hyperorality and dietary change. The language score included agrammatic, apraxic and logopenic speech and impaired semantic memory. The sensorimotor score comprised cortical sensory loss, apraxia and alien limb syndrome, and sensorimotor deficits. Participants completed formal cognitive testing including the Addenbrookes Cognitive Examination - Revised (ACE-R) and the Frontal Assessment Battery (FAB), which is sensitive to executive dysfunction in FTLD syndromes. ${ }^{14}$ Participants' nearest relative or carer completed the revised Cambridge Behavioural Inventory (CBI-R).

\section{Magnetic resonance spectroscopy}

Participants were scanned at the Wolfson Brain Imaging Centre, University of Cambridge on a Siemens 3T PRISMA system. A T1-weighted structural sequence (MPRAGE $\mathrm{TR}=2000 \mathrm{~ms}, \mathrm{TE}=2.93 \mathrm{~ms}, \mathrm{TI}=850 \mathrm{~ms}, \mathrm{FA}=8^{\circ}, 208$ slices, $1.1 \mathrm{~mm}$ isotropic voxels) was acquired for localisation of the spectroscopy regions of interest (ROI) and partial volume correction. Single-voxel magnetic resonance spectra were acquired serially from $2 \times 2 \times 2 \mathrm{~cm}$ voxels placed manually by the same operator (AGM) over the right inferior frontal gyrus, right superior temporal gyrus and right primary visual cortex using anatomical landmarks. Spectra were acquired using a short-echo semiLASER sequence $(64 \text { repetitions, TR/TE }=5000 / 28 \mathrm{~ms})^{15,16}$ with FASTESTMAP shimming ${ }^{17}$ and water-peak flip angle and VAPOR water suppression. ${ }^{18}$ The 64 individual repetitions were saved separately then corrected for eddy current effect, frequency and phase shifts using MRspa (Dinesh Deelchand, University of Minnesota, www. cmrr.umn.edu/downloads/mrspa). All spectra were visually inspected for quality control. Spectra from 18 voxels (FTLD n=9, Control n=9) were excluded due to movement artefact, inadequate water suppression and/or lipid contamination.

Neurochemicals between 0.5 and 4.2ppm were quantified using LCModel (Version 6.2-3) ${ }^{19}$ with water scaling and a simulated basis set that included an experimentally-acquired macromolecule spectra. The fractions of grey matter, white matter and CSF were obtained from segmentation of the MP2RAGE imaging using the standard voxel-based morphometry pre-processing pipeline in SPM12. Nine metabolites had a mean Cramer Rao Lower Bound lower than 20 and were saved for further analysis. Metabolites with correlation $\leq-0.3$ were reported together: (i) NAA and NAAG, (ii) choline and glycerophosphocholine, (iii) creatine and phosphocreatine, (iv) glucose and taurine and (v) ascorbate and glutathione. Measures of scan quality, including water linewidth and signal to noise, are reported in table 1. 
Table 1: Magnetic resonance spectroscopy quality metrics. Values for control and FTLD-associated syndromes are the group mean (standard deviation in parentheses).CRLB=Cramer Rao Lower Bound. IFG=inferior frontal gyrus, $\mathrm{STG}=$ superior temporal gyrus, $\mathrm{V} 1=$ right primary visual cortex. $\mathrm{t}=$ Welch $\mathrm{t}$-test comparing all FTLD syndromes with control, $\mathrm{df}=$ degrees of freedom.

\begin{tabular}{|c|c|r|r|r|r|r|}
\hline Region & Quality measure & \multicolumn{1}{c|}{ Control } & \multicolumn{1}{c|}{ FTLD } & \multicolumn{1}{c|}{ t } & \multicolumn{1}{c|}{ df } & \multicolumn{1}{c|}{ p } \\
\hline \multirow{5}{*}{ Right IFG } & Glutamate CRLB & $3.9(0.4)$ & $4.8(1.6)$ & -3.7 & 71 & $<0.001$ \\
& NAA+NAAG CRLB & $2.0(0.2)$ & $2.1(0.5)$ & -1.8 & 92.4 & 0.08 \\
& Water linewidth & $7.3(0.8)$ & $6.3(1.2)$ & 5.13 & 95.5 & $<0.001$ \\
& Signal to noise ratio & $56.4(5.2)$ & $47.3(8.6)$ & 6.53 & 95.8 & $<0.001$ \\
\hline \multirow{4}{*}{ Right STG } & Glutamate CRLB & $4.3(1.0)$ & $4.9(1.4)$ & -2.5 & 82 & 0.02 \\
& NAA+NAAG CRLB & $2.0(0.3)$ & $2.1(0.6)$ & -1.6 & 76.7 & 0.12 \\
& Water linewidth & $9.00(0.9)$ & $8.4(1.6)$ & 1.99 & 77.4 & 0.05 \\
& Signal to noise ratio & $49.7(9.3)$ & $45.3(11.3)$ & 1.95 & 81.2 & 0.05 \\
\hline \multirow{5}{*}{ Right V1 } & Glutamate CRLB & $5.1(2.9)$ & $4.7(2.8)$ & 0.64 & 59.5 & 0.53 \\
& NAA+NAAG CRLB & $1.9(0.8)$ & $1.8(0.7)$ & 0.62 & 56.6 & 0.54 \\
& Water linewidth & $7.5(0.8)$ & $7.2(0.8)$ & 1.38 & 63.2 & 0.17 \\
& Signal to noise ratio & $58.1(16.0)$ & $61.6(13.8)$ & -1 & 55.1 & 0.32 \\
\hline
\end{tabular}

\section{Statistical analysis}

A generalised linear model was used to remove the effect of age, sex and partial volume (of grey and white matter) from the metabolite concentrations. This model was weighted with the metabolite Cramer Rao Lower Bound and the residuals used for further analysis. The tissue correction method was the same as Murley at et (2020). ${ }^{20}$ Factorial analysis of variance (ANOVA) was used to compare nineteen metabolite concentrations across three brain regions and between five groups. Dunnett's post hoc test was used to explore differences between control participants and the FTLD syndrome subtypes. Welch's t-test was used to test for differences in cognitive tests between healthy participants and those with a FTLD syndrome.

Since both cognition and metabolites are multivariate, we used canonical correlation analysis (CCA) to compare the frontal and temporal lobe metabolite profiles (as measured by MRS) and cognitive and behavioral impairment (as measured by the ACE-R, FAB, CBI and clinician rating of behavioral, language and sensorimotor impairment). CCA is a multivariate technique that measures the association between two sets of variables. ${ }^{21}$ It uses a data-driven approach to reveal latent, common factors, or canonical covariates, underlying these associations. ${ }^{6,22}$ All variables were standardised into z-scores before CCA. The CCA was permuted 5000 times to determine significance and ensure stability of the final components.

\section{Data availability}

Anonymised data are available on reasonable request for academic use, subject to restrictions required to protect participant confidentiality. 
Murley et al. Page 6

\section{Results}

Participant characteristics are summarised in Table 2. There was no significant difference in the age and sex distributions of the patient and control groups. Patients had marked global cognitive and behavioral impairment, as rated by direct patient measures (ACE-R, FAB), structured carer interview (CBI-R) and clinician rating based on history and examination (Table 2).

Table 2: Participant demographics and cognitive test results. FTLD=all FTLD-related syndromes, bvFTD=behavioral variant frontotemporal dementia, $\mathrm{PSP}=$ progressive supranuclear palsy, $\mathrm{CBS}=$ corticobasal syndrome, $\mathrm{PPA}=$ primary progressive aphasia (all subtypes), ACE-R: Addenbrooke's Cognitive Examination - Revised, FAB: Frontal Assessment Battery, CBI-R: Cambridge Behavioral Inventory - Revised. Clinician behavior, sensorimotor and language are the sum of the presence of features in each domain, $t=$ Welch $t$-test comparing all FTLD syndromes with control, $*=\chi^{2}$ test, $\mathrm{F}=$ ANOVA of FTLD syndrome subtypes, Post-hoc pairwise Tukey's tests $(\mathrm{p}<0.05)$ : $\mathrm{a}=\mathrm{bvFTD}$ vs PSP, $\mathrm{b}=\mathrm{bvFTD}$ vs CBS, c=bvFTD vs PPA,d=PPA vs PSP, e=PPA vs CBS, $\mathrm{f}=\mathrm{CBS}$ vs PSP, NA = no variance in control group.

\begin{tabular}{|c|c|c|c|c|c|c|c|c|c|c|c|}
\hline & Control & $\begin{array}{c}\text { FTLD } \\
(\mathbf{a l l})\end{array}$ & $\mathbf{t}$ & $\mathbf{p}$ & $\mathbf{b v F T D}$ & $\mathbf{P S P}$ & $\mathbf{C B S}$ & $\mathbf{P P A}$ & $\mathbf{F}$ & $\mathbf{p}$ & Post-hoc \\
\hline $\mathrm{N}$ & 38 & 60 & & & 11 & 26 & 11 & 12 & & & \\
\hline Age & $\begin{array}{c}67.9 \\
(5.8)\end{array}$ & $\begin{array}{c}69.56 \\
(7.23)\end{array}$ & -1.23 & 0.222 & $\begin{array}{c}63.7 \\
(7.6)\end{array}$ & $\begin{array}{c}71.7 \\
(6.6)\end{array}$ & $\begin{array}{c}71.2 \\
(7.1)\end{array}$ & $\begin{array}{c}68.8 \\
(5.8)\end{array}$ & 3.94 & 0.013 & $\mathrm{a}$ \\
\hline $\begin{array}{c}\text { Sex } \\
(\mathrm{M} / \mathrm{F})\end{array}$ & $19 / 19$ & $33 / 27$ & $0.23^{*}$ & 0.529 & $7 / 4$ & $14 / 12$ & $5 / 6$ & $7 / 5$ & $0.80^{*}$ & 0.848 & \\
\hline ACE-R Total & $\begin{array}{c}96.5 \\
(2.4)\end{array}$ & $\begin{array}{c}73.98 \\
(20.53)\end{array}$ & 8.4 & $<0.001$ & $\begin{array}{c}72.4 \\
(18.3)\end{array}$ & $\begin{array}{c}78.2 \\
(14.9)\end{array}$ & $\begin{array}{c}78.5 \\
(18.7)\end{array}$ & $\begin{array}{c}62.1 \\
(30.2)\end{array}$ & 2.02 & 0.122 & \\
\hline FAB & $\begin{array}{c}17.1 \\
(0.8)\end{array}$ & $\begin{array}{c}11.66 \\
(4.52)\end{array}$ & 9.1 & $<0.001$ & $\begin{array}{c}10.7 \\
(5.4)\end{array}$ & $\begin{array}{c}12.1 \\
(3.8)\end{array}$ & $\begin{array}{c}11.3 \\
(5.7)\end{array}$ & $\begin{array}{c}12 \\
(4.4)\end{array}$ & 0.27 & 0.850 & \\
\hline CBI-R Total & $6.2(6.1)$ & $\begin{array}{c}54.65 \\
(32.97)\end{array}$ & -11.1 & $<0.001$ & $\begin{array}{c}89.3 \\
(22.7)\end{array}$ & $\begin{array}{c}52 \\
(31.6)\end{array}$ & $\begin{array}{c}46.9 \\
(27.8)\end{array}$ & $\begin{array}{c}35.8 \\
(27)\end{array}$ & 7.46 & $<0.001$ & $\mathrm{a}, \mathrm{b}, \mathrm{c}$ \\
\hline $\begin{array}{c}\text { Clinician: } \\
\text { behavior }\end{array}$ & $0(0)$ & $\begin{array}{c}3.6 \\
(3.37)\end{array}$ & $\mathrm{NA}$ & $\mathrm{NA}$ & $\begin{array}{c}8.9 \\
(1.3)\end{array}$ & $\begin{array}{c}3.3 \\
(2.7)\end{array}$ & $\begin{array}{c}1.5 \\
(1.4)\end{array}$ & $\begin{array}{c}1.4 \\
(1.7)\end{array}$ & 31.7 & $<0.001$ & $\mathrm{a}, \mathrm{b}, \mathrm{c}$ \\
\hline $\begin{array}{c}\text { Clinician: } \\
\text { language }\end{array}$ & $0(0)$ & $\begin{array}{c}2.52 \\
(2.28)\end{array}$ & $\mathrm{NA}$ & $\mathrm{NA}$ & $\begin{array}{c}2.6 \\
(2.6)\end{array}$ & $\begin{array}{c}1.5 \\
(1.5)\end{array}$ & $\begin{array}{c}2.4 \\
(1.6)\end{array}$ & $\begin{array}{c}4.8 \\
(2.4)\end{array}$ & 8.2 & $<0.001$ & $\mathrm{c}, \mathrm{d}, \mathrm{e}$ \\
\hline $\begin{array}{c}\text { Clinician: } \\
\text { sensorimotor }\end{array}$ & $0(0)$ & $\begin{array}{c}1.15 \\
(1.34)\end{array}$ & $\mathrm{NA}$ & $\mathrm{NA}$ & $\begin{array}{c}0.1 \\
(0.3)\end{array}$ & $\begin{array}{c}0.6 \\
(0.8)\end{array}$ & $\begin{array}{c}3.1 \\
(0.9)\end{array}$ & $\begin{array}{c}1.6 \\
(1.2)\end{array}$ & 29.34 & $<0.001$ & $\mathrm{~b}, \mathrm{c}, \mathrm{d}, \mathrm{e}, \mathrm{f}$ \\
\hline
\end{tabular}

Our analyses proceeded in two stages. First, we used single-voxel magnetic resonance spectroscopy (MRS) to measure nine metabolites in the frontal, temporal and occipital lobes. Metabolite concentrations, after correction for age, sex, and atrophy within the voxel, varied significantly by region and diagnosis (region $\mathrm{x}$ metabolite $\mathrm{x}$ diagnosis interaction $\mathrm{F}_{(64)}=1.73, \mathrm{p}<0.001$ ).

In other words, there were regionally specific effects of disease, for some but not all metabolites. These can be understood in the context of the first order interactions and main effects (Table 3) as follows. Metabolite concentrations varied by region but there was no region by diagnosis interaction $\left(\mathrm{F}_{(8)}=1.23 \mathrm{p}=0.29\right)$, validating the effective partial volume correction of the metabolite concentrations. Main effect analysis showed that the region by metabolite by diagnosis interaction was due to differences in neurotransmitter glutamate and neuronal marker $\mathrm{N}$-acetyl-aspartate and $\mathrm{N}$ acetyl-asparate-glutamate (NAA+NAAG) concentration. Post hoc analyses revealed lower concentrations of the neurotransmitter glutamate and neuronal marker $\mathrm{N}$-acetyl aspartate in bvFTD and PSP compared to controls (Figure 1). A glutamate deficit was also found in PSP in the right 
superior temporal gyrus (Figure 1). $\mathrm{N}$-acetyl aspartate concentrations were low in the right visual cortex in PSP. Despite these significant group differences, there was wide variation in metabolite concentrations in all groups (Figure 1).

Correcting for the brain volume differences between groups, had a significant effect on the variation in metabolite concentrations (Factorial ANOVA including corrected and uncorrected data: region $\mathrm{x}$ metabolite $\mathrm{x}$ uncorrected/corrected $\mathrm{x}$ diagnosis $\left.\mathrm{F}_{(64)}=7.94 \mathrm{p}<0.001\right)$.
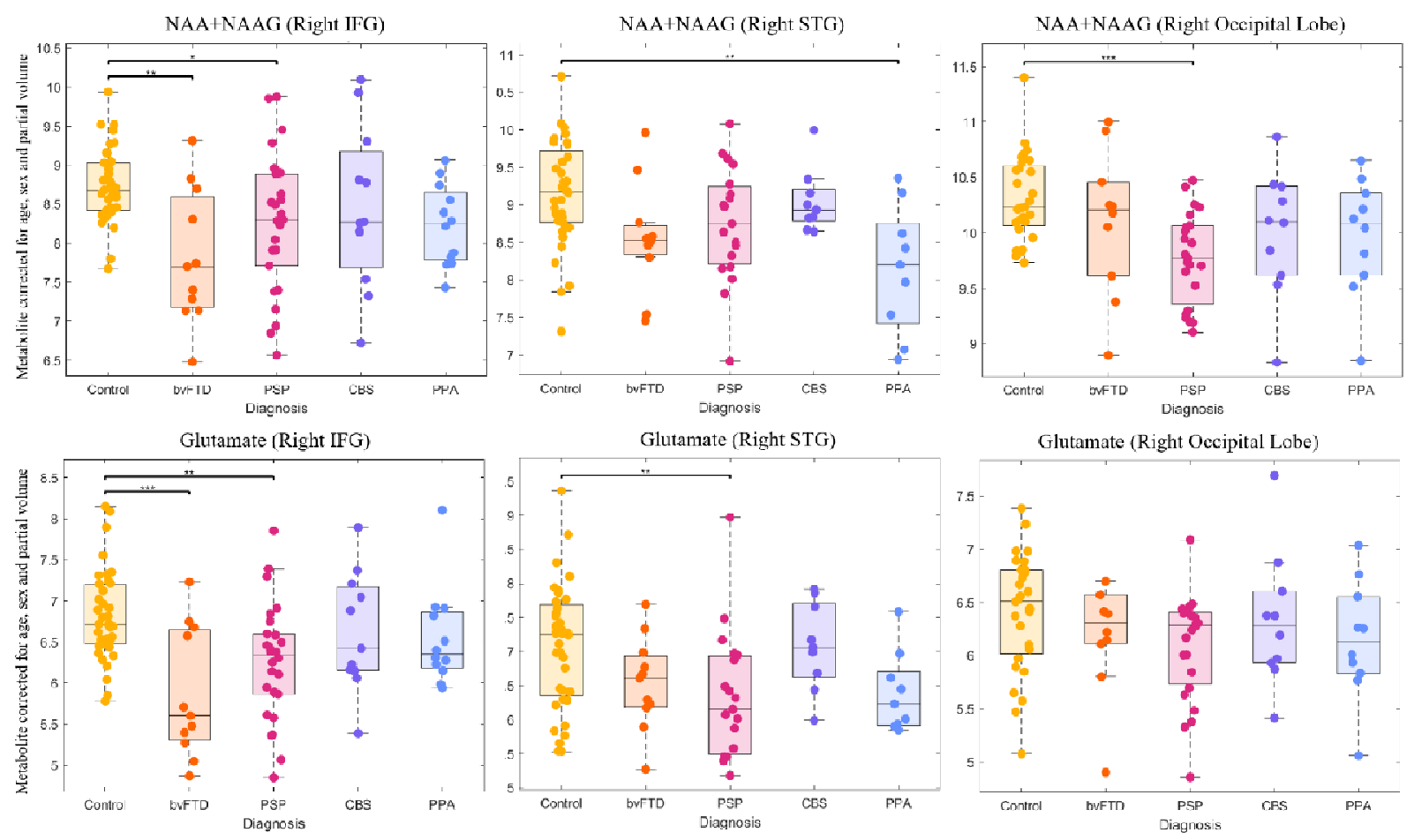

Figure 1: Boxplots of MRS metabolites. Boxplots of metabolites that are significantly different between FTLD-related syndromes and control participants after post-hoc testing from ANOVA of all metabolites, regions and diagnoses. Metabolite values are corrected for age, sex and partial volume. ${ }^{*} \mathrm{p}<0.05, * * \mathrm{p}<0.01, * * * \mathrm{p}<0.001$

Second, we used canonical correlation analysis to test the association between (i) frontal and temporal lobe metabolites and (ii) behavioral and cognitive impairments. This revealed one significant component $(\mathrm{R}=0.85, \mathrm{p}<0.001)$. This component indicated an association between low glutamate and $\mathrm{N}$-acetyl aspartate in the right inferior frontal gyrus (Figure 2A) and the combination of executive dysfunction, low verbal fluency, low frontal assessment battery scores, and high clinician and carer rating of behavioral impairment (Figure 2D). All FTLD-associated syndromes had strong positive correlations in this component (Figure 2B), and this association was stronger in patients than controls (Figure 2B). There was second component with a trend ( $\mathrm{p}=0.037$, not surviving correction for multiple comparisons) with a negative loading from right superior temporal gyrus glutamate, and correlation with carer ratings of impaired everyday skills and abnormal behavior). 
medRxiv preprint doi: https://doi.org/10.1101/2021.01.11.21249589; this version posted January 13, 2021. The copyright holder for this preprint (which was not certified by peer review) is the author/funder, who has granted medRxiv a license to display the preprint in perpetuity.

It is made available under a CC-BY 4.0 International license .

Murley et al. Page 8
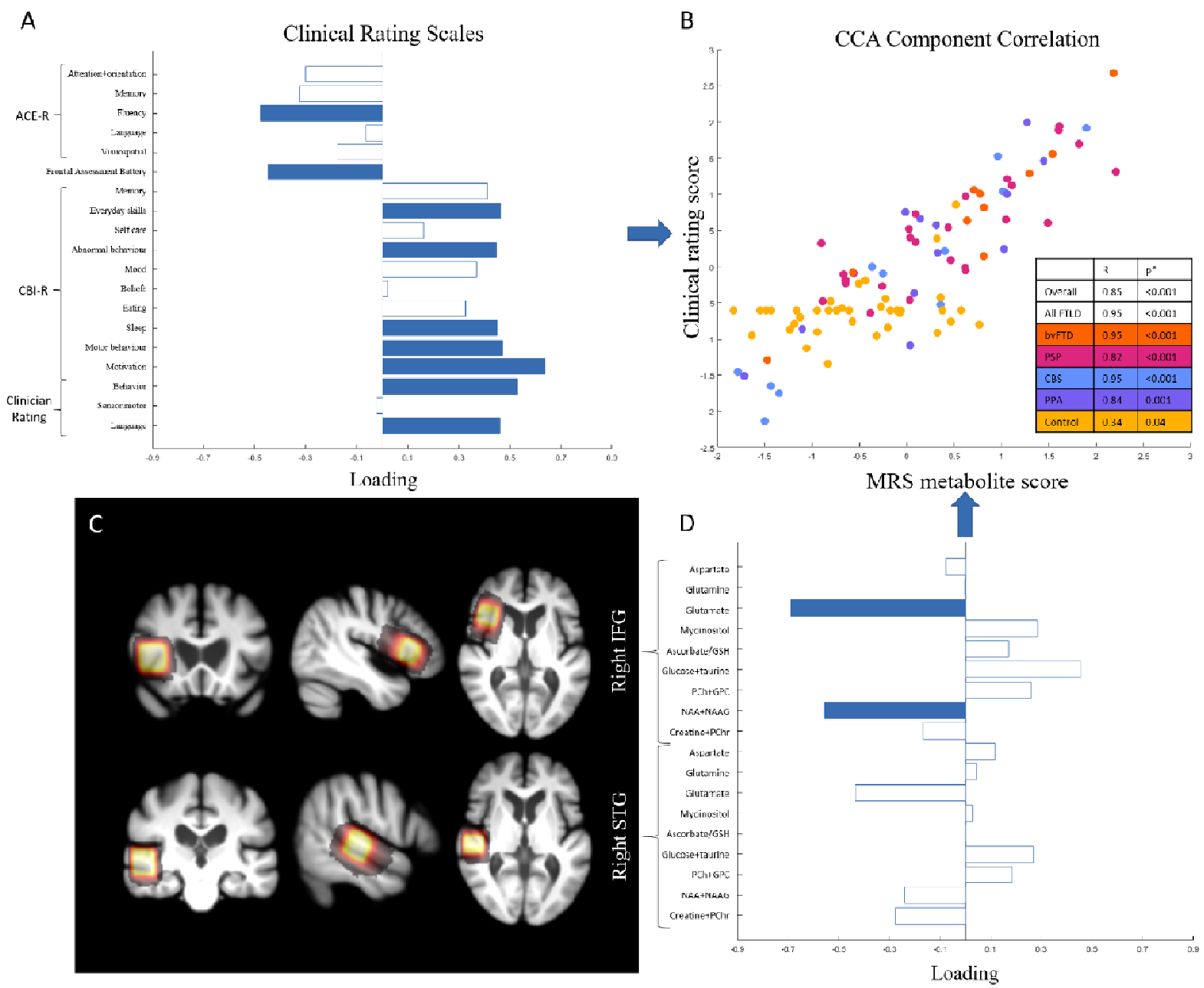

Figure 2: Canonical correlation analysis of MRS and cognitive and behavioral measures. First component from canonical correlation analysis of MRS metabolites and cognitive and behavioral measures. 2A: Loadings from cognitive measures on the first CCA component. Bars colored blue have statistically significant loadings (FWE p<0.05) after permutation testing. Worse performance indicated by Negative ACE-R, positive CBI-R and clinician rating indicate worse cognition/behavior. 2B: First CCA component correlation, color-coded by group. 2C: Map of all participants' MRS ROIs superimposed on a mean structural image. 2D: MRS metabolite loadings onto the first CCA component. GSH:glutathione, PCh: phosphocholine, GPC: glycerophosphocholine, NAA: N-acetyl-aspartate, NAAG: N-acetylaspartate-glutamate, PChr: phosphocreatine Bars colored blue have statistically significant loadings $(\mathrm{FWE} p<0.05)$ after permutation testing. 
Table 3 Full factorial analysis of variance showing first order results and simple main effect of diagnosis. Regions: IFG= right inferior frontal gyrus, STG=right superior temporal gyrus, V1=right primary visual cortex. Diagnoses: bvFTD, PSP, CBS, PPA, Control. Metabolites: Aspartate, Glutamine, Glutamate, myo-inositol, N-acetyl aspartate (including N-acetylaspartate-glutamate), choline $=$ choline and glycerophosphocholine, creatine $=$ creatine and phosphocreatine

\begin{tabular}{|c|c|c|c|c|c|}
\hline \multicolumn{6}{|c|}{ ANOVA (between and within subject effects) } \\
\hline \multicolumn{2}{|r|}{ Cases } & Sum of Squares & df & $\mathbf{F}$ & $\mathbf{p}$ \\
\hline \multicolumn{2}{|r|}{ Region } & 4.05 & 2 & 4.52 & 0.013 \\
\hline \multicolumn{2}{|c|}{ Region $x$ Diagnosis } & 4.40 & 8 & 1.23 & 0.288 \\
\hline \multicolumn{2}{|c|}{ Metabolite } & 10280.33 & 8 & 2841.54 & $<0.001$ \\
\hline \multicolumn{2}{|c|}{ Metabolite $\mathrm{x}$ Diagnosis } & 31.33 & 32 & 2.17 & $<0.001$ \\
\hline \multicolumn{2}{|c|}{ Region $\mathrm{x}$ Metabolite } & 149.26 & 16 & 55.58 & $<0.001$ \\
\hline \multicolumn{2}{|c|}{ Region $\mathrm{x}$ Metabolite $\mathrm{x}$ Diagnosis } & 18.54 & 64 & 1.73 & $<0.001$ \\
\hline \multicolumn{2}{|c|}{ Diagnosis } & 5.29 & 4 & 0.91 & 0.464 \\
\hline \multicolumn{6}{|c|}{ Simple Main Effects - Diagnosis } \\
\hline Level of ROI & Level of Metabolite & Sum of Squares & df & $\mathbf{F}$ & $\mathbf{p}$ \\
\hline \multirow{9}{*}{$\begin{array}{c}\text { Frontal } \\
\text { (Right IFG) }\end{array}$} & Aspartate & 1.19 & 4 & 1.87 & 0.125 \\
\hline & Glutamine & 0.80 & 4 & 1.05 & 0.391 \\
\hline & Glutamate & 7.67 & 4 & 5.73 & $<0.001$ \\
\hline & Myoinositol & 2.94 & 4 & 1.41 & 0.240 \\
\hline & Ascorbate + glutathione & 0.43 & 4 & 1.41 & 0.239 \\
\hline & Glucose + taurine & 3.87 & 4 & 2.34 & 0.064 \\
\hline & Choline & 0.10 & 4 & 0.61 & 0.654 \\
\hline & NAA + NAAG & 8.83 & 4 & 4.16 & 0.004 \\
\hline & Creatine & 0.41 & 4 & 0.63 & 0.646 \\
\hline \multirow{9}{*}{$\begin{array}{c}\text { Temporal } \\
\text { (Right STG) }\end{array}$} & Aspartate & 0.58 & 4 & 0.14 & 0.965 \\
\hline & Glutamine & 1.19 & 4 & 1.02 & 0.404 \\
\hline & Glutamate & 7.26 & 4 & 2.71 & 0.037 \\
\hline & Myoinositol & 1.17 & 4 & 0.85 & 0.499 \\
\hline & Ascorbate + glutathione & 0.40 & 4 & 0.45 & 0.776 \\
\hline & Glucose + taurine & 1.72 & 4 & 0.98 & 0.426 \\
\hline & Choline & 0.24 & 4 & 1.52 & 0.206 \\
\hline & NAA + NAAG & 9.84 & 4 & 4.67 & 0.002 \\
\hline & Creatine & 1.98 & 4 & 2.07 & 0.095 \\
\hline \multirow{9}{*}{$\begin{array}{l}\text { Occipital } \\
\text { (Right V1) }\end{array}$} & Aspartate & 0.94 & 4 & 0.50 & 0.736 \\
\hline & Glutamine & 0.56 & 4 & 1.26 & 0.295 \\
\hline & Glutamate & 1.54 & 4 & 1.33 & 0.267 \\
\hline & Myoinositol & 0.74 & 4 & 0.36 & 0.838 \\
\hline & Ascorbate + glutathione & 0.18 & 4 & 0.67 & 0.614 \\
\hline & Glucose + taurine & 1.48 & 4 & 0.64 & 0.634 \\
\hline & Choline & 0.02 & 4 & 0.33 & 0.860 \\
\hline & NAA + NAAG & 3.15 & 4 & 3.36 & 0.014 \\
\hline & Creatine & 0.34 & 4 & 0.52 & 0.719 \\
\hline
\end{tabular}




\section{Discussion}

There are two principal results of this study: (i) that $\mathrm{N}$-acetyl aspartate and glutamate are reduced in the prefrontal cortex of people with diverse syndromes associated with frontotemporal lobar degeneration; and (ii) these metabolite differences, as measured by in vivo magnetic resonance spectroscopy, correlate with the severity of cognitive and behavioral impairments. A group-wise deficit in these metabolites was seen in bvFTD and PSP, but the association with cognitive and behavioral impairment was in found every patient group. These findings have two implications. First, they strengthen the evidence that metabolite and neurotransmitter deficits are a promising treatment target for pharmacological amelioration of clinical features. Second, because the metabolite deficits in brain tissue are identified after stringent atrophy correction, and correlate with cognition even in syndromes like PSP in which lateral prefrontal cortical atrophy is not marked, the spectroscopy might detect early, even pre-symptomatic, disease before patients develop brain atrophy.

The hypotheses of this study were based on post mortem neurochemistry and pre-clinical evidence $^{23,24}$, supported by later ultra-high field MRS. ${ }^{20,25}$ We predicted an association in all FTLDassociated syndromes between glutamate concentration and clinically relevant carer- and clinicianmeasures of behavioral impairment. Pharmacological correction of such neurochemical deficits might be a tractable target for symptom treatment, especially where these have neurotransmitter functions in addition to metabolic roles. Such symptomatic treatment is a priority given the severe sequelae of cognitive impairment in FTLD. ${ }^{7,23,26}$ However, it remains unclear to what extent our findings reflect a potentially reversible deficit of synaptic glutamate. MRS measures the total pool of unbound glutamate, involved in neuron and glia metabolism, protein synthesis and neurotransmission. ${ }^{27}$ The NMDA antagonist memantine has been used commonly off-licence in frontotemporal dementia treatments, but this is ineffective and anecdotally can worsen cognition in some patients. ${ }^{28}$ Further work is therefore required to understand the relationship between synaptic loss in syndromes associated with FTLD and glutamate deficits. ${ }^{29}$ Healthy age-matched participants also had a weak but statistically significant correlation on this component, corroborating with previous research on glutamate deficits in healthy ageing. ${ }^{30}$

$\mathrm{N}$-acetyl aspartate (NAA) is an abundant amino acid in the central nervous system and comprises the largest peak in the proton spectroscopy spectrum. ${ }^{31}$ NAA is concentrated in neurons and is proposed as a marker of neuronal density, health and function. ${ }^{31}$ Deficits are found in a wide range of neurological diseases associated with neuronal loss including Alzheimer's disease ${ }^{32}$, stroke $^{33}$ and traumatic brain injury. ${ }^{34} \mathrm{NAA}$ is therefore not specific to the proteinopathies associated with FTLD $^{25}$. However, our findings replicate previous studies in FTLD-related syndromes ${ }^{35-40}$ and suggest that NAA levels are a sensitive measure of neuronal loss, over and above structural MRI estimates of brain atrophy. As part of a multi-model MRI battery, NAA spectroscopy may be a useful endpoint in experimental medicine studies, and to understand phenotypic heterogeneity. ${ }^{41}$

We did not replicate the previous studies that reported reduced choline $e^{45}$ and elevated myoinositol $^{45,46}$, despite a relatively large sample size, high field strength and use of a consensus sequence and analysis pipelines. ${ }^{47}$ We did find that different partial volume correction methods 
change the conclusions regarding metabolite concentrations. It is therefore possible that our results are overly stringent in partial volume correction. This has important implications for the clinical use of MRS as some correction methods, e.g. creatine ratios, may be less accurate in measuring metabolite levels in residual brain tissue.

Canonical correlation analysis indicated that glutamate and NAA concentrations in the right inferior frontal gyrus were associated with executive dysfunction and behavioral impairment. The first canonical correlate represented concordant neuropsychological, carer and clinician ratings. This emphasises that frontal NAA and glutamate deficits are associated with clinically relevant cognitive impairment, building on earlier correlations with specific neuropsychological tasks. ${ }^{20}$

Metabolites with lower loadings on the first canonical correlate were not statistically significant, as estimated by permutation testing, but may still be of interest. For example, myo-inositol, which is concentrated in glia and elevated with neuroinflammation, had a positive loading. Neuroinflammation has been identified by TSPO-ligand position emission tomography, in bvFTD, PPA and PSP ${ }^{42,43}$, where it is not only elevated but also prognostic of a more rapid decline. ${ }^{44}$

Our results are relevant to the nosology of syndromes associated with FTLD. The diseases of bvFTD, PSP, CBS, PPA are clinically and pathologically distinct in their classical phenotypes, and there are critical differences in underlying neuropathology even where there is tauopathy. We therefore used the current consensus diagnostic criteria for each clinical disorder. However, the clinical phenotypes associated with FTLD do not respect the diagnostic boundaries and many patients develop clinical features that would meet criteria for more than one disorder. ${ }^{6}$ We have proposed an alternative, transdiagnostic, approach to encompass clinical heterogeneity and phenotypic overlap. ${ }^{6}$ This approach, emphasising commonalities in clinic-pathological correlations across the spectrum of FTLD, is supported by our data. The association between prefrontal glutamate, NAA and cognition was observed in all FTLD syndromes jointly, and individually. This is consistent with the metabolite deficits being down-stream of the disease-specific causes of brain injury, and more proximate to the clinical phenotype.

Our study has several limitations. First, this study omits to report GABA concentrations, despite preclinical and ultra-high field MRS evidence of GABA deficits in bvFTD and PSP ${ }^{20,23-25}$. This omission is because of the low sensitivity and inadequate spectral resolution for GABA using semiLASER sequence at 3T. Second, the deficits identified by magnetic resonance spectroscopy are unlikely to be specific to one proteinopathy. Participants were diagnosed according to the clinical diagnostic criteria ${ }^{2-5}$ which have variable clinicopathological correlation. ${ }^{48,49}$ In particular, bvFTD is associated with either 3R or 4R tau or TDP-43 pathology, whereas PSP has a high clinicopathological correlation with 4R tau. Our cohort has limited pathological confirmation of the diagnosis but clinicopathological correlations in the PIPPIN study as whole match those found elsewhere. ${ }^{6,7}$ Therefore, while spectroscopy may be a valuable measure of early disease and/or disease progression it is unlikely to differentiate FTLD syndromes according to their underlying proteinopathies. Third, due to small numbers we grouped non-fluent, semantic and logopenic variants of PPA together, although these sub-groups have different clinical and neuropathological 
medRxiv preprint doi: https://doi.org/10.1101/2021.01.11.21249589; this version posted January 13, 2021. The copyright holder for this preprint

(which was not certified by peer review) is the author/funder, who has granted medRxiv a license to display the preprint in perpetuity.

It is made available under a CC-BY 4.0 International license .

Murley et al. Page 12

features. Fourth, MRS accuracy can be affected by participant movement and other factors which may be greater in the FTLD cohort. To mitigate this we used a consensus guideline-recommended sequence and analysis pipeline ${ }^{47}$ and a within-participant control region in the occipital lobe. Finally, our findings are limited to the single brain regions we imaged. Advances in whole brain MRSI sequences may allow simultaneous measurement of metabolites in multiple regions, better accounting for the clinical and neuropathological heterogeneity in FTLD.

In conclusion, $\mathrm{N}$-acetyl aspartate and glutamate deficits in the prefrontal cortex are associated with loss of executive function and behavioral impairment in each of the major syndromes associated with frontotemporal lobar degeneration (bvFTD, PSP, CBS, PPA), even after correction for atrophy. Magnetic resonance spectroscopy can detect clinically relevant differences in metabolites in vivo and may be a valuable adjunct to multi-modal imaging for detecting disease in early stage disease, monitoring progression and response to disease-modifying treatment, and stratification for experimental studies of restorative pharmacology. 


\section{References}

1. MacKenzie IRA, Neumann M, Bigio EH, et al. Nomenclature and nosology for neuropathologic subtypes of frontotemporal lobar degeneration: An update. Acta Neuropathol. 2010;119:1-4.

2. Rascovsky K, Hodges JR, Knopman D, et al. Sensitivity of revised diagnostic criteria for the behavioural variant of frontotemporal dementia. Brain [online serial]. 2011;134:2456-2477. Accessed at: http://www.ncbi.nlm.nih.gov/entrez/query.fcgi?cmd=Retrieve $\& d b=P u b M e d \& d o p t=C i t a t i o n \& 1$ ist_uids=21810890.

3. Höglinger GU, Respondek G, Stamelou M, et al. Clinical diagnosis of progressive supranuclear palsy: The movement disorder society criteria. Mov Disord. 2017;32:853-864.

4. Armstrong MJ, Litvan I, Lang AE, et al. Criteria for the diagnosis of corticobasal degeneration. Neurology. 2013;80:496-503.

5. Gorno-Tempini ML, Hillis AE, Weintraub S, et al. Classification of primary progressive aphasia and its variants. Neurology [online serial]. 2011;76:1006-1014. Accessed at: http://www.ncbi.nlm.nih.gov/entrez/query.fcgi?cmd=Retrieve \&db=PubMed\&dopt=Citation \&l ist_uids=21325651.

6. Murley AG, Coyle-Gilchrist I, Rouse MA, et al. Redefining the multidimensional clinical phenotypes of frontotemporal lobar degeneration syndromes. Brain [online serial]. 2020;143:1555-1571. Accessed at: https://academic.oup.com/brain/article/143/5/1555/5841762.

7. Murley AG, Rouse MA, Coyle-Gilchrist I, et al. Predicting loss of independence and mortality in frontotemporal lobar degeneration syndromes. Epub 2020.

8. Mioshi E, Foxe D, Leslie F, et al. The impact of dementia severity on caregiver burden in frontotemporal dementia and alzheimer disease. Alzheimer Dis Assoc Disord. 2013;27:68-73.

9. Kril JJ, Halliday GM. Pathological staging of frontotemporal lobar degeneration. J Mol Neurosci. 2011;45:379-383.

10. Hughes LE, Rittman T, Robbins TW, Rowe JB. Reorganization of cortical oscillatory dynamics underlying disinhibition in frontotemporal dementia. Brain. 2018;141:2486-2499.

11. Hughes LE, Ghosh BCP, Rowe JB. Reorganisation of brain networks in frontotemporal dementia and progressive supranuclear palsy. NeuroImage Clin. 2013;2:459-468.

12. Coyle-Gilchrist ITS, Dick KM, Patterson K, et al. Prevalence, characteristics, and survival of frontotemporal lobar degeneration syndromes. Neurology [online serial]. 2016;86:1736-1743. Accessed at: http://www.neurology.org/lookup/doi/10.1212/WNL.0000000000002638. Accessed August 11, 2016.

13. Lansdall CJ, Coyle-Gilchrist ITS, Jones PS, et al. Apathy and impulsivity in frontotemporal lobar degeneration syndromes. Brain [online serial]. 2017;140:1792-1807. Accessed at: https://academic.oup.com/brain/article/140/6/1792/3806842.

14. Hurtado-Pomares M, Carmen Terol-Cantero M, Sánchez-Pérez A, Peral-Gómez P, ValeraGran D, Navarrete-Muñoz EM. The frontal assessment battery in clinical practice: a 
medRxiv preprint doi: https://doi.org/10.1101/2021.01.11.21249589; this version posted January 13, 2021. The copyright holder for this preprint (which was not certified by peer review) is the author/funder, who has granted medRxiv a license to display the preprint in perpetuity.

It is made available under a CC-BY 4.0 International license .

Murley et al. Page 14

systematic review. Int J Geriatr Psychiatry. 2018;33:237-251.

15. Öz G, Tkáč I. Short-echo, single-shot, full-intensity proton magnetic resonance spectroscopy for neurochemical profiling at $4 \mathrm{~T}$ : Validation in the cerebellum and brainstem. Magn Reson Med. 2011;65:901-910.

16. Deelchand DK, Adanyeguh IM, Emir UE, et al. Two-site reproducibility of cerebellar and brainstem neurochemical profiles with short-echo, single-voxel MRS at 3T. Magn Reson Med. 2015;73:1718-1725.

17. Gruetter R, Tkáč I. Field mapping without reference scan using asymmetric echo-planar techniques. Magn Reson Med. 2000;43:319-323.

18. Tkac I, Starcuk Z, Choi I-Y, Gruetter R. In vivo1H NMR spectroscopy of rat brain at $1 \mathrm{~ms}$ echo time. Magn Reson Med [online serial]. 1999;41:649-656. Accessed at:

http://doi.wiley.com/10.1002/\%28SICI\%2915222594\%28199904\%2941\%3A4\%3C649\%3A\%3AAID-MRM2\%3E3.0.CO\%3B2-G.

19. Provencher SW. Estimation of metabolite concentrations from localizedin vivo proton NMR spectra. Magn Reson Med [online serial]. United States: LCModel; 1993;30:672-679. Accessed at: s-provencher.com/pub/LCModel/manual/manual.pdf.

20. Murley AG, Rouse MA, Jones PS, et al. GABA and glutamate deficits from frontotemporal lobar degeneration are associated with disinhibition. Brain [online serial]. 2020;143:34493462. Accessed at: https://academic.oup.com/brain/advancearticle/doi/10.1093/brain/awaa305/5952714.

21. Wang H-T, Smallwood J, Mourao-Miranda J, et al. Finding the needle in a high-dimensional haystack: Canonical correlation analysis for neuroscientists. Neuroimage [online serial]. 2020;216:116745. Accessed at: http://arxiv.org/abs/1812.02598.

22. Tsvetanov KA, Henson RNA, Tyler LK, et al. Extrinsic and intrinsic brain network connectivity maintains cognition across the lifespan despite accelerated decay of regional brain activation. J Neurosci. 2016;36:3115-3126.

23. Murley AG, Rowe JB. Neurotransmitter deficits from frontotemporal lobar degeneration. Brain [online serial]. 2018;141:1263-1285. Accessed at: http://academic.oup.com/brain/advance-article/doi/10.1093/brain/awx327/4823510.

24. Warmus BA, Sekar DR, McCutchen E, et al. Tau-mediated NMDA receptor impairment underlies dysfunction of a selectively vulnerable network in a mouse model of frontotemporal dementia. J Neurosci [online serial]. 2014;34:16482-16495. Accessed at: http://www.jneurosci.org/cgi/doi/10.1523/JNEUROSCI.3418-14.2014.

25. Öz G, Alger JR, Barker PB, et al. Clinical proton MR spectroscopy in central nervous system disorders. Radiology [online serial]. 2014;270:658-679. Accessed at: http://www.pubmedcentral.nih.gov/articlerender.fcgi?artid=4263653\&tool=pmcentrez\&render type $=$ abstract.

26. Benussi A, Alberici A, Buratti E, et al. Toward a glutamate hypothesis of frontotemporal dementia. Front Neurosci. 2019;13:1-9.

27. Zhou Y, Danbolt NC. Glutamate as a neurotransmitter in the healthy brain. J Neural Transm. 2014;121:799-817. 
medRxiv preprint doi: https://doi.org/10.1101/2021.01.11.21249589; this version posted January 13, 2021. The copyright holder for this preprint (which was not certified by peer review) is the author/funder, who has granted medRxiv a license to display the preprint in perpetuity.

It is made available under a CC-BY 4.0 International license .

Murley et al. Page 15

28. Boxer AL, Knopman DS, Kaufer DI, et al. Memantine in patients with frontotemporal lobar degeneration: A multicentre, randomised, double-blind, placebo-controlled trial. Lancet Neurol [online serial]. Elsevier Ltd; 2013;12:149-156. Accessed at: http://dx.doi.org/10.1016/S1474-4422(12)70320-4.

29. Holland N, Jones PS, Savulich G, et al. Synaptic Loss in Primary Tauopathies Revealed by [11C]UCB-J Positron Emission Tomography. Mov Disord. 2020;35:1834-1842.

30. Zahr NM, Mayer D, Rohlfing T, et al. In vivo glutamate measured with magnetic resonance spectroscopy: Behavioral correlates in aging. Neurobiol Aging. 2013;34:1265-1276.

31. Moffett JR, Ross B, Arun P, Madhavarao CN, Namboodiri MAA. N-Acetylaspartate in the CNS: From Neurodiagnostics to Neurobiology. Prog Neurobiol [online serial]. 2007;81:89_ 131. Accessed at: http://www.ncbi.nlm.nih.gov/pmc/articles/PMC1919520/.

32. Marjańska M, Riley McCarten J, Hodges JS, Hemmy LS, Terpstra M. Distinctive Neurochemistry in Alzheimer's Disease via $7 \mathrm{~T}$ in Vivo Magnetic Resonance Spectroscopy. J Alzheimer's Dis. 2019;68:559-569.

33. Muñoz Maniega S, Cvoro V, Chappell FM, et al. Changes in NAA and lactate following ischemic stroke: A serial MR spectroscopic imaging study. Neurology. 2008;71:1993-1999.

34. Garnett MR, Blamire AM, Corkill RG, Cadoux-Hudson TAD, Rajagopalan B, Styles P. Early proton magnetic resonance spectroscopy in normal-appearing brain correlates with outcome in patients following traumatic brain injury. Brain. 2000;123:2046-2054.

35. Tedeschi G, Litvan I, Bonavita S, et al. Proton magnetic resonance spectroscopic imaging in progressive supranuclear palsy, Parkinson's disease and corticobasal degeneration. Brain. 1997;120:1541-1552.

36. Ernst T, Chang L, Melchor R, Mark Mehringer C. Frontotemporal dementia and early Alzheimer disease: Differentiation with frontal lobe H-1 MR spectroscopy. Radiology [online serial]. Radiological Society of North America; 1997;203:829-836. Accessed at: http://dx.doi.org/10.1148/radiology.203.3.9169712.

37. Chen Q, Boeve BF, Tosakulwong N, et al. Frontal lobe 1H MR spectroscopy in asymptomatic and symptomatic MAPT mutation carriers. Neurology. 2019;93:E758-E765.

38. Chawla S, Wang S, Moore P, et al. Quantitative proton magnetic resonance spectroscopy detects abnormalities in dorsolateral prefrontal cortex and motor cortex of patients with frontotemporal lobar degeneration. J Neurol. 2010;257:114-121.

39. Coulthard E, Firbank M, English P, et al. Proton magnetic resonance spectroscopy in frontotemporal dementia. J Neurol. 2006;253:861-868.

40. Cheong I, Deelchand DK, Eberly LE, et al. Neurochemical correlates of functional decline in amyotrophic lateral sclerosis. J Neurol Neurosurg Psychiatry. 2019;90:294-301.

41. Cope TE, Weil RS, Düzel E, Dickerson BC RJ. Advances in neuroimaging to support translational medicine in dementia. J Neurol Neurosurg Psychiatry.

42. Bevan-Jones WR, Cope TE, Jones PS, et al. Neuroinflammation and protein aggregation colocalize across the frontotemporal dementia spectrum. Brain [online serial]. 2020;143:10101026. Accessed at: http://biorxiv.org/content/early/2019/01/21/525642.abstract. 
medRxiv preprint doi: https://doi.org/10.1101/2021.01.11.21249589; this version posted January 13, 2021. The copyright holder for this preprint

(which was not certified by peer review) is the author/funder, who has granted medRxiv a license to display the preprint in perpetuity.

It is made available under a CC-BY 4.0 International license.

Murley et al. Page 16

43. Malpetti M, Passamonti L, Rittman T, et al. Neuroinflammation and Tau Colocalize in vivo in Progressive Supranuclear Palsy. Ann Neurol. 2020;88:1194-1204.

44. Malpetti M, Passamonti L, Jones PS, et al. Neuroinflammation predicts disease progression in progressive supranuclear palsy. medRxiv. Epub 2020.:1-23.

45. Mihara M, Hattori N, Abe K, Sakoda S, Sawada T. Magnetic resonance spectroscopic study of Alzheimer's disease and frontotemporal dementia/Pick complex. Neuroreport [online serial]. 2006;17. Accessed at: http://journals.lww.com/neuroreport/Fulltext/2006/03200/Magnetic_resonance_spectroscopic_ study_of.13.aspx.

46. Kantarci K, Petersen RC, Boeve BF, et al. 1H MR spectroscopy in common dementias. Neurology [online serial]. 2004;63:1393-1398. Accessed at:

http://www.pubmedcentral.nih.gov/articlerender.fcgi?artid=2766798\&tool=pmcentrez\&render type $=$ abstract.

47. Öz G, Deelchand DK, Wijnen JP, et al. Advanced single voxel $1 \mathrm{H}$ magnetic resonance spectroscopy techniques in humans: Experts' consensus recommendations . NMR Biomed [online serial]. Epub 2020 Jan 10.:1-18. Accessed at: https://onlinelibrary.wiley.com/doi/abs/10.1002/nbm.4236.

48. Perry DC, Brown JA, Possin KL, et al. Clinicopathological correlations in behavioural variant frontotemporal dementia. Brain [online serial]. 2017;140:3329-3345. Accessed at: http://academic.oup.com/brain/article/doi/10.1093/brain/awx254/4371604/Clinicopathological -correlations-in-behavioural.

49. Gazzina S, Respondek G, Compta Y, et al. Neuropathological validation of the MDS-PSP criteria with PSP and other frontotemporal lobar degeneration. bioRxiv [online serial]. Epub 2019.:520510. Accessed at: https://www.biorxiv.org/content/10.1101/520510v1.abstract. 